\title{
Brief Report:
}

\section{Effect of dietary restraint on fruit and vegetable intake following}

\author{
implementation intentions
}

Nicholas A. Troop

Address for correspondence:

School of Psychology, University of Hertfordshire, College Lane, Hatfield, Herts AL10

9AB, U.K.; Email n.a.troop@herts.ac.uk; Tel 01707286451

Running head: Implementation intentions and dietary restraint

Word length: 2,500 (including titles, abstract and references) + 1 table 


\title{
Brief Report: Effect of dietary restraint on fruit and vegetable intake following implementation intentions
}

\begin{abstract}
This study explored whether the effects of implementation intentions on increasing fruit and vegetable intake were moderated by dietary restraint. 208 participants were randomly allocated to control or implementation intention conditions where they were asked to write down when, where and how they would increase their fruit and vegetable intake. Implementation intentions increased fruit and vegetable intake but only in participants scoring low (not high) on rigid dietary restraint. Motives underlying fruit and vegetable consumption may be different for restrained and unrestrained eaters. Efforts to increase their intake may need to be tailored, e.g. through motivational rather than situational cues.
\end{abstract}

Keywords: implementation intentions, diet, dietary restraint 


\section{Introduction}

Intentions are strong predictors of behaviour (Armitage \& Conner, 2001) although social cognition models such as the Theory of Planned Behaviour (TPB: Ajzen, 1991) cannot explain how individuals translate intentions into actions. Gollwitzer (1999) distinguishes between goal intentions (the specification of an end goal, e.g. "I intend to reach $x$ ") and implementation intentions (the specification of the when, where and how that will lead to goal attainment, e.g. "When situation $x$ arises, I will perform $y$ "). Meta-analysis shows that implementation intentions have a medium-to-large effect on behaviour $(d=.65)$ (Gollwitzer \& Sheeren, 2006).

Eating 5 or more portions of fruit and vegetables every day has significant health benefits (Foods Standards Agency, 2006) and so forms the basis of the UK recommended daily amount (RDA). Studies generally show that implementation intentions can increase fruit and vegetable consumption in adult, student and adolescent samples (de Nooijer, de Vet, Brug, \& de Vries, 2006; Gratton, Povey \& ClarkCarter, 2007; Kellar \& Abraham, 2005; Prestwich, Ayres, \& Lawton, 2008; Stadler, Oettingen, \& Gollwitzer, 2010) although a study with cardiac patients found no such effect (Jackson, Lawton, Knapp, Raynor, Conner, Lowe, \& Closs, 2005). However, improvements are modest (around $1 / 2$ portion per day)and the effectiveness of implementation intentions in increasing the number of people eating RDA (rather than simply increasing the average number of portions eaten in a population) is uncertain. 
Another question concerns the impact of dietary restraint on the effectiveness of implementation intentions. Dietary restraint refers to cognitively mediated efforts to combat the urge to eat because of concerns about weight and shape (Herman \& Mack, 1975). Since fruit and vegetables are low in fat, restrained eaters might be particularly susceptible to efforts to increase their consumption. However, dieting includes both healthy (e.g. eating more fruit and less fat) and unhealthy (e.g. skipping meals, fasting) dietary practices (Lattimore \& Halford, 2003). It can also lead to a rebound effect where restrained eaters consume more calories and gain more weight than unrestrained eaters, particularly when stressed (Roberts, Troop, Connan, Campbell \& Treasure, 2007). So it is possible that, in spite of plans to eat healthily, restrained eaters may be less successful at implementing these plans. This study explores the effects of rigid dietary restraint (associated with eating disturbances and binge eating) and flexible dietary restraint (associated with successful weight loss and maintenance) (Westenhoefer, Stunkard \& Pudel, 1999).

Therefore, while the simplicity of implementation intentions is appealing, its impact on consumption of fruit and vegetables is not certain. This study determines whether implementation intentions increase eating fruit and vegetables to RDA and whether they are equally effective in both restrained (rigid versus flexible) and unrestrained eaters.

\section{Method}




\section{Participants}

A total of 220 non-vegetarian university students were recruited via lectures and snowballing although 12 did not complete the 1 week follow-up. Of the remaining 208 participants, 67 were men and 141 were women. Mean age was 20.5 (s.d. = 2.3) and mean BMI was $22.8 \mathrm{~kg} / \mathrm{m}^{2}$ (s.d. = 4.9). Most participants were white $(47 \%)$, black $(27 \%)$ or Asian (24\%) and most were single (64\%) or had a boyfriend/girlfriend (33\%) with only $3 \%$ married or cohabiting.

\section{Measures}

TPB variables: Attitude was assessed using 2 items, subjective norms using 1 item and perceived behavioural control (PBC) using 6 items. Intention to eat more fruit and vegetables was assessed by a single item, "I intend to eat more fruit and vegetables in the next few days". All items were rated on 5-point scales ranging from 1-strongly disagree to 5-strongly agree and variables were created by calculating means of each item.

Dietary restraint was assessed using the 14-item Cognitive Restraint Scale (Westenhoefer et al, 1999) assessing both rigid and flexible dieting. Scores range between 7-18 and 7-24 for flexible and rigid control respectively.

Intake of fruit and vegetables were assessed on scales ranging from 0 (no portions) to 4 (4 or more portions) (Prochaska \& Sallis, 2004). Scores for fruit and vegetable intake 
were summed giving values ranging from 0 to 8 and recoded as a categorical variable indicating whether participants met recommended daily amounts or not (RDA $\geq 5$ ). The measure at baseline asked about average daily intake over the previous week. The follow-up measure asked about daily intake, measured on 5 consecutive days.

Internal reliabilities for multi-item scales were between .65 and .80. Questionnaires have established validity apart from the TPB questionnaire which was developed for the present study. Higher scores mean more of the construct in all measures.

\section{Procedure}

Following ethical approval from the relevant ECDA at the University of Hertfordshire, participants were randomly allocated to control $(n=99)$ and experimental $(n=109)$ groups (there were no significant differences on any baseline variables, all $p$-values > .24). All participants completed the same baseline questionnaires (in the order described above) while those in the experimental group also received the implementation intention instruction at the end of the questionnaire: "Fruit and vegetables are good sources of nutrition as they contain many vitamins and minerals. There is evidence to show that people who eat plenty of fruit and vegetables are less likely to develop a range of chronic diseases. However, most of us don't eat enough fruit and vegetables. Please write in below when, where and how you will introduce more fruit and vegetables into your diet over the next week. You are free to choose how you will do this but please formulate your plans in as much detail as possible. Please pay 
particular attention to the situations in which you will implement these plans. For example, you might plan how you could replace five other snacks or foods you normally eat with fruit and vegetables. Or you could see how you can incorporate them into meals that you would normally eat anyway". Experimental participants were asked to formulate plans regardless of their actual level of intention to increase fruit and vegetable intake. All participants completed 5 daily fruit and vegetable intake sheets over the following week. These were collected at the end of that week and average daily intake was calculated.

\section{Results}

Only $23 \%(n=48)$ of participants ate at RDA (i.e. ate 5 or more portions of fruit and vegetables). Participants eating at RDA were significantly higher than those eating below RDA on flexible (means [s.d.s] were 12.5 [2.5] versus 10.5 [2.4], $\mathrm{t}_{206}=5.06, \mathrm{p}<.001$ ) and rigid dietary restraint (means [s.d.s] were 14.4 [4.1] versus 11.6 [3.4], $\mathrm{t}_{206}=4.69, \mathrm{p}<$ .001). They also scored higher on attitude (means [s.d.s] were 4.4 [.7] versus 4.1 [.7], $\mathrm{t}_{206}$ $=2.89, \mathrm{p}<.01$ ), PBC (means [s.d.s] were $3.6[.6]$ versus $3.4[.6], t_{206}=2.14, p<.05$ ) and intention (means [s.d.s] were 3.7 [.9] versus 3.2 [1.0], $\mathrm{t}_{206}=3.39, \mathrm{p}<.001$ ). No other variables differed significantly (t-values $<1.57, \mathrm{p}>.12$ ).

To determine the effect of implementation intentions and dietary restraint on increasing fruit and vegetable intake to RDA, only those 160 participants who did not meet RDA at baseline were included. Eating RDA at follow-up was regressed onto 
intervention group, dietary restraint and their interactions, controlling for demographic and social cognition variables at baseline. This model is summarised in Table 1 and is significantly predictive, correctly identifying $86.3 \%$ of participants. Higher BMI and greater intention predicted a greater likelihood of eating at RDA at follow-up. Intervention group was also significantly predictive (those in the implementation intention group were more likely to eat at RDA at follow up: $18.5 \%$ versus $7.6 \%$ ) and rigid dietary restraint was marginally significant.

\section{$\underline{\text { Table } 1 \text { about here }}$}

There was a significant interaction between intervention group and rigid dietary restraint. Based on a median split for the rigid dietary restraint scale (median $=12$ ), implementation intentions had no significant effect on fruit and vegetable intake in those scoring high in rigid dietary restraint (17\% [5/29] versus $13 \%$ [4/30] for implementation intention and control participants respectively, $\left.\chi^{2}=.00, p=.96\right)$. In those low in rigid dietary restraint, implementation intentions did have a significant effect (19\% [10/52] versus 4\% [2/49] for implementation intention and control participants respectively, $\left.\chi^{2}=4.20, p<.05\right)$

\section{Discussion}

At baseline, only $23 \%$ of participants were eating fruit and vegetables at FSA recommended levels. However, those eating RDA had greater levels of dietary restraint 
as well as a more positive attitude, greater perceived control and greater intention to eat fruit and vegetables. In those eating below RDA, greater BMI, greater intention and the formation of an implementation intention increased the likelihood of eating fruit and vegetables to RDA at follow-up. The effect of implementation intentions was moderated by dietary restraint whereby implementation intentions predicted a greater likelihood of eating RDA in those who were low in rigid dietary restraint but not those high in rigid dietary restraint. This is meaningful since it is rigid, rather than flexible, restraint that relates to greater eating disturbances (Westenhoefer et al., 1999).

There are at least two possible reasons to account for the fact that people high in rigid dietary restraint do not increase their fruit and vegetable intake after making plans to do so. Firstly, the justification provided in this study for increasing fruit and vegetable intake was based on health consequences which may not be the primary motivation for restrained eaters to eat fruit and vegetables. It may be that theirs is a different motivation, for example that fruit and vegetables are low in calories or fat). Mental contrasting to allow individuals to identify the most positive outcome and then imagine the most critical obstacle can be used in conjunction with implementation intentions (Stadler et al., 2010) which increases its effectiveness and this could be explored in future research in restrained eaters. However, the most positive stated outcome for restrained eaters may be weight loss which, for people of normal weight, may not be objectively desirable or healthy (even if it is subjectively desired). It may also perpetuate 
a cycle of restriction and overeating, known to be a risk for bulimia nervosa and weight gain (Stice, 2001, 2002).

A second possibility is that emotional factors may override cognitive plans in restrained eaters. It may be that the plan to eat more vegetables is forgotten when the trigger for overeating high calorie foods is often negative emotions. Forming implementation intentions following motivational cues rather than situational ones (i.e. the reasons why people elicit a behaviour rather than when and where they elicit a behaviour) is more effective at decreasing unhealthy snacking (Adriaanse, de Ridder, \& de Wit, 2009). Future research could explore whether this approach is useful in restrained eaters.

Limitations should be acknowledged. Although the sample size was acceptable and commensurate with other studies in this area, all participants were students and results may not be generalizable. In addition, the measure of fruit and vegetable intake was a brief self-report questionnaire. Finally, although the 1-week follow-up is similar to other studies using implementation intentions on fruit and vegetable intake, it is necessary to determine whether the effect in unrestrained eaters persists over longer periods.

In conclusion, implementation intentions to increase fruit and vegetable intake have an effect on unrestrained eaters but not people high in rigid dietary restraint. Future research should evaluate whether modified or enhanced approaches to the formation 
of implementation intentions can improve diet in restrained as well as unrestrained eaters. 


\section{References}

Adriaanse MA, de Ridder DT, and de Wit JB (2009) Finding the critical cue:

Implementation intentions to change one's diet work best when tailored to personally relevant reasons for unhealthy eating. Personality and Social Psychology Bulletin 35: 6071.

Ajzen I (1991) The theory of planned behavior. Organizational Behavior and Human Decision Processes 50: 179-211.

Armitage CJ and Connor M (2001) Efficacy of the theory of planned behaviour: A metaanalytic review. British Journal of Social Psychology 40: 471-499.

de Nooijer J, de Vet E, Brug J, and de Vries NK (2006) Do implementation intentions help to turn good intentions into higher fruit intakes? Journal of Nutrition Education and Behavior 38: 25-29.

Food Standards Agency (2006). FSA nutrient and food based guidelines for UK institutions. London, UK: FSA.

Gollwitzer P (1999) Implementation intentions: Strong effects of simple plans. American Psychologist 54: 493-503. 
Gollwitzer P, and Sheeran P (2006) Implementation intentions and goal achievement: A meta-analysis of effects and processes. Advances in Experimental Social Psychology 38: 249-268.

Gratton L, Povey R, and Clark-Carter D (2007) Promoting children's fruit and vegetable consumption: Interventions using the Theory of Planned Behaviour as a framework. British Journal of Health Psychology 12: 639-650.

Herman C, and Mack D (1975) Restrained and unrestrained eating. Journal of Personality 43: 647-660.

Jackson C, Lawton R, Knapp P, Raynor D, Conner M, Lowe C, and Closs S (2005) Beyond intention: Do specific plans increase health behaviours in patients in primary care? A study of fruit and vegetable consumption. Social Science \& Medicine 60: 2383-2391.

Kellar I and Abraham C (2005) Randomized controlled trail of a belief research-based intervention promoting fruit and vegetable consumption. British Journal of Health Psychology 10: 543-558.

Lattimore P and Halford J (2003) Adolescence and the diet-dieting disparity: Healthy food choice or risky health behaviour. British Journal of Health Psychology 8: 451-463. 
Prestwich A, Ayres K, and Lawton R (2008) Crossing two types of implementation intentions with a protection motivation intervention for the reduction of saturated fat intake: A randomized trial. Social Science \& Medicine 67: 1550-1558.

Prochaska J and Sallis J (2004) Reliability and validity of a fruit and vegetable screening measure for adolescents. Journal of Adolescent Health 34: 163-165.

Roberts C, Troop N, Connan F, Treasure J and Campbell I (2007) The effects of stress on body weight: biological and psychological predictors of BMI. Obesity 15: 3045-3055.

Stadler G, Oettingen G, and Gollwitzer PM (2010) Intervention effects of information and self-regulation on eating fruits and vegetables over two years. Health Psychology 29: $274-283$.

Stice E (2001) A prospective test of the Dual-Pathway Model of bulimic pathology: Mediating effects of dieting and negative affect. Journal of Abnormal Psychology 110: 124-135.

Stice E (2002) Risk and maintenance factors for eating pathology: A meta-analytic review. Psychological Bulletin 128: 825-848. 
Westenhoefer J, Stunkard AJ, and Pudel V (1999) Validation of the flexible and rigid control dimensions of dietary restraint. International Journal of Eating Disorders 26: 5364. 
$\underline{\text { Table 1. Regression analysis predicting eating } 5 \text { or more portions of fruit and vegetables }}$ at Follow-up

\begin{tabular}{lll}
\hline & Wald & Exp(B) \\
\hline Age & 1.29 & .84 \\
Sex & .02 & .92 \\
BMI & $4.62^{*}$ & 1.11 \\
Attitude & .01 & .95 \\
Subjective norm & .35 & .85 \\
PBC & .04 & 1.10 \\
Intention & $7.02^{* *}$ & 2.42 \\
Group & $4.12^{*}$ & .28 \\
Flexible restraint & 1.58 & .08 \\
Rigid restraint & $3.81+$ & 43.68 \\
Group $\times$ Flexible restraint & 1.75 & 4.10 \\
Group $\times$ Rigid restraint & $4.13^{*}$ & .11 \\
\hline Overall ${ }^{2}$ & $23.55^{*}$ & \\
Negelkerke R & .253 & \\
\% correct & $86.3 \%$ & \\
\hline
\end{tabular}

$* p<.05, * * p<.01, * * * p<.001,+p=.051$ 